\title{
PENTINGNYA PROSES DOKUMENTASI KEPERAWATAN
}

\author{
Ade Herawati Sahputri \\ adehera92@gmail.com
}

\section{Latar Belakang}

Dokumentasi asuhan keperawatan merupakan catatan tentang tanggapan/respon klien terhadap kegiatan-kegiatan pelaksanaan keperawatan secara menyeluruh, sistematis dan terstruktur sebagai pertanggunggugatan terhadap tindakan yang dilakukan perawat terhadap klien dalam melaksanakan asuhan keperawatan dengan menggunakan pendekatan proses keperawatan (Prabowo, 2016). Apabila pendokumentasian tidak dilakukan dengan lengkap akan dapat menurunkan mutu pelayanan keperawatan karena tidak akan dapat mengidentifikasi sejauh mana tingkat keberhasilan asuhan keperawatan yang telah diberikan. dalam aspek legal perawat tidak mempunyai bukti tertulis jika suatu hari nanti klien menuntut ketidakpuasan akan pelayanan keperawatan (Yanti, 2013).

Bukti tertulis pelayanan yang diberikan kepada pasien oleh tenaga keperawatan bertujuan untuk menghindari kesalahan, tumpang tindih dan ketidak lengkapan informasi. Undangundang nomor 44 tahun 2009 pasal 52 ayat 1 menyatakan bahwa rumah sakit wajib melakukan pencatatan dan pelaporan tentang semua kegiatan penyelenggaraan rumah sakit dalam bentuk system informasi manajemen rumah sakit. Permenkes No.269/MENKES/PER/III/2008 tentang rekam medis pada pasal 1 ayat 1 , menyatakan bahwa rekam medik adalah berkas yang berisikan catatan dan dokumen tentang identitas pasien, pemeriksaan, pengobatan, tindakan dan pelayanan lain yang telah diberikan kepada pasien.

Berdasarkan permenkes tersebut maka tenaga keperawatan mempunyai kewajiban untuk mendokumentasikan setiap asuhan keperawatan yang diberikan kepada pasien. Profesi keperawatan merupakan profesi yang memiliki resiko hukum, kesalahan perawatan yang mengakibatkan kecacatan atau kematian bagi pasien dapat menyeret perawat ke pengadilan, karenanya segala aktifitas yang dilakukan terhadap pasien harus di dokumentasikan dengan baik dan jelas. Dokumentasi menjadi elemen penting dari perawatan pasien, memungkinkan komunikasi antara tim perawatan dan seluruh pergeseran keperawatan, memberikan catatan hukum perawatan yang diberikan kepada pasien dan bertindak sebagai alat untuk membantu mengelola perawatan pasien (Boucher, 2012).

Dokumentasi sebagai alat bukti tanggung jawab dan tanggung gugat dari perawat dalam 
menjalankan tugasnya. Dokumentasi merupakan catatan otentik dalam penerapan manajemen asuhan keperawatan professional. Perawat professional diharapkan dapat menghadapi tuntutan tanggung jawab dan tanggung gugat terhadap segala tindakan yang dilakukannya. Bila terjadi suatu masalah yang berhubungan dengan profesi keperawatan, maka dokumentasi tersebut dapat dapat dipergunakan sebagai barang bukti di pengadilan (Setiadi, 2012)

Melalui dokumentasi keperawatan akan dapat dilihat sejauhmana peran dan fungsi perawat dalam memberikan asuhan keperawatan kepada klien. Hal ini akan bermanfaat bagi peningkatan mutu pelayanan (Handayaningsih, 2009). Apabila dokumentasi tidak lengkap maka dapat terjadi resiko-resiko seperti kesalahan dalam komunikasi, dalam perencanaan tindakan, dalam pengambilan tindakan, sehingga dapat menjerat perawat karena tidak adanya dokumentasi resmi yang bernilai hukum dan dapat mengakibatkan menurunnya mutu asuhan keperawatan. Dokumentasi keperawatan merupakan alat vital dalam mengurangi tingkat kematian dan kejadian pasien yang merugikan (Boucher, 2012)

\section{Metode}

Metode yang digunakan dalam kajian ini adalah metode literature review yaitu metode dengan cara membaca dari berbagai sumber seperti jurnal online, skripsi, dan ebook serta membandingkan isi dari berbagai sumber yang dibaca dan menyimpulkan dalam hasil kajian yang didapatkan pada jurnal, skripsi, e-book mengenai dokumentasi keperawatan.

\section{Hasil}

Dokumentasi secara umum merupakan suatu catatan otentik atau semua warkat asli yang dapat dibuktikan atau dijadikan bukti dalam persoalan hukum, sedangkan dokumentasi keperawatan merupakan bukti pencatatan dan pelaporan yang dimiliki perawat dalam melakukan catatan perawatan yang berguna untuk kepentingan klien, perawat, dan tim kesehatan dalam memberikan pelayanan kesehatan dengan dasar komunikasi yang akurat dan lengkap secara tertulis dengan tanggung jawab perawat (Hidayat, 2002).

Dokumentasi merupakan bagian integral proses keperawatan, bukan sesuatu yang berbeda dari metode problem solving. Dokumentasi proses keperawatan mencakup pengkajian, identifikasi masalah, perencanaan, tindakan, dan evaluasi terhadap klien (Nursalam, 2009). Menurut Nursalam (2001), tujuan utama dari dokumentasi keperawatan adalah mengkonfirmasikan data pada semua anggota tim kesehatan, memberikan bukti untuk tujuan evaluasi asuhan keperawatan, sebagai tanggung jawab dan tanggung gugat, sebagai metode pengembangan ilmu keperawatan. 
Salah satu fungsi profesional perawat adalah mengevaluasi respon pasien terhadap asuhan keperawatan. Perawat profesional bertanggungjawab untuk menatalaksanakan masalah pasien yang bertambah kompleks dan mengkoordinasikan perawatan pasien ke berbagai tingkat tenaga kesehatan. Dokumentasi harus dengan jelaa mengkomunikasikan penilaian dan evaluasi perawat terhadap status pasien. Kemampuan perawat untuk membuat perubahan dalam hasil yang didapat harus ditunjukan dalam praktik dan dalam pencatatan

Salah satu tugas dan tanggungung jawab perawat adalah melakukan pendokumentasian mengenai intervensi yang telah dilakukan, akan tetapi akhir-akhir ini tanggung jawab peraw

Oleh karena perubahan tersebut maka perawat perlu menyusun suatu model dokumentasi baru yang lebih efisien dan lebih bermakna dalam pencatatan dan penyimpanan. Maka pendokumentasian itu sangat penting bagi perawat karena sebagai dasar hukum tindakan keperawatan yang sudah di lakukan jika suatu saat nanti ada tuntutan dari pasien.

Ada beberapa model pendokumentasian keperawatan yaitu : SOR (Source Oriented Record), POR (Problem Oriented Record), CBE ( Charting by Exeption ), PIE ( Problem Intervention and Evaluation ), FOCUS (Process Oriented System ). Model ini memiliki kekurangan dan kelebihan masing-masing.

\section{Pembahasan}

Potter dan Perry (1994) memberikan panduan sebagai petunjuk cara mendokumentasikan yang benar, sebagai berikut: a). Jangan menghapus dengan menggunakan cairan penghapus atau mencoret-coret tulisan yang salah ketika mencatat, karena akan tampak perawat seakan akan menyembunyikan informasi atau merusak catatan. Adapun cara yang benar adalah dengan membuat garis lurus pada tulisan yang salah (usahakan tulisan yang salah masih bisa dibaca), lalu diparaf pada bagian terakhir kalimat yang salah kemudian diikuti dengan tulisan kata yang benar. b). Jangan menulis komentar yang bersifat mengkritik pasien atau tenaga kesehatan lainnya, karena pernyataan tersebut dapat dinilai sebagai perilaku tidak professional atau asuhan keperawatan yang tidak bermutu. c.) Koreksi semua kesalahan sesegera mungkin. d.)Bila kesalahan tidak segera diperbaiki maka dapat menyebabkan kesalahan tindakan pula. e.) Catatan harus akurat, valid dan reliabel. Pastikan yang ditulis adalah fakta, jangan berspekulasi atau menuliskan pikiran sendiri. f.) Jangan biarkan bagian kosong pada catatan perawat, karena orang lain dapat menambah informasi yang tidak benar pada bagian yang kosong tersebut. g.) Semua catatan harus dapat dibaca dan ditulis dengan tinta. h.) Menulis hanya untuk diri sendiri karena perawat bertanggunggugat atas informasi yang telah ditulisnya. 
Jangan menulis untuk orang lain.i.) Hindari penggunaan istilah yang bersifat tidak umum. j.) Memulai dokumentasi dengan waktu dan akhiri dengan tanda tangan dan nama jelas.

\section{Model Dokumentasi Keperawatan}

\section{SOR (SOURCE ORIENTED RECORD)}

Pengertian

Sistem model pendokumentasian ini berorientasi pada sumber informasi. Dokumentasi ini memungkinkan setiap anggota tim kesehatan membuat catatannya sendiri dari hasil observasi. Hasil pengkajian tersebut dikumpulkan menjadi satu. Setiap anggota dapat melaksanakan aktifitas profesionalnya secara mandiri tanpa tergantung dengan tim kesehatan lainnya.

Model ini menempatkan catatan atas dasar disiplin orang atau sumber yang mengelola pencatatan. Bagian penerimaan klien mempunyai lembar isian tersendiri, dokter menggunakan lembar untuk mencatat instruksi, lembaran riwayat penyakit dan perkembangan penyakit, perawat menggunakan catatan keperawatan, begitu pula disiplin lain mempunyai catatan masing-masing.

\section{POR (PROBLEM ORIENTED RECORD)}

Pengertian

Model dokumentasi ini merupakan pengembangan dari dokumentasi model SOR. Dokumentasi ini merupakan alat yg efektif guna mendokumentasikan sistem pelayanan kesehatan yang berorientasi pada klien. Pendokumentasian ini memungkinkan digunakan oleh multidisplin tenaga kesehatan dengan pendekatan pemecahan masalah. Model pendokumentasian ini mengarahkan pada ide dan pemikiran anggota tim, sehingga masingmasing anggota tim bisa saling mengemukakan pandangannya dalam memberikan pelayanan kesehatan kepada klien. Model ini juga memudahkan dalam perencanaan tindakan keperawatan dan memungkinkan antar anggota tim kesehatan saling berkomunikasi dengan baik.

Model ini memusatkan data tentang klien didokumentasikan dan disusun menurut masalah klien. Sistem dokumentasi jenis ini mengintegrasikan semua data mengenai masalah yang dikumpulkan oleh dokter, perawat atau tenaga kesehatan lain yang terlibat dalam pemberian layanan kepada klien. Penekanannya tidak pada siapa yang memberi pelayanan, tetapi pada masalah untuk apa asuhan kesehatan klien itu diberikan. 


\section{MODEL DOKUMENTASI CBE (CHARTING BY EXEPTION)}

Model dokumentasi ini hanya mencatat secara naratif hasil pengkajian yang menyimpang dari data normal atau standar yang ada. Model pendokumentasian seperti ini mengurangi penggunaan waktu yang lama, karena lebih menekankan pada data yang penting saja, mudah untuk mencari data yang penting, pencatatan langsung ketika memberikan asuhan, pengkajian yang terstandar, meningkatkan komunikasi antara tenaga kesehatan, lebih mudah melacak respons klien dan lebih murah.

Dokumentasi model CBE mengidentifikasikan 3 (tiga) komponen penting, yaitu:

1. Lembar alur (flowsheet).

2. Pencatatan dilaksanakan berdasarkan standar praktik. Format dokumentasi diletakkan di tempat tidur klien sehingga dapat segera digunakan untuk pencatatan dan tidak perlu memindahkan data.

\section{PROBLEM INTERVENSION AND EVALUATION (PIE)}

Sistem dokumentasi ini menggunakan pendekatan orientasi-proses dokumentasi dengan penekanan pada proses keperawatan dan diagnosa keperawatan. Penggunaan format ini sangat tepat digunakan pada pemberian asuhan keperawatan primer. Pada keadaan klien yang akut, perawat primer dapat melaksanakan dan mencatat pengkajian waktu klien masuk dan pengkajian sistem tubuh dan diberi tanda PIE setiap hari.

Karakteristik model pendokumentasian PIE adalah pengkajian klien dimulai saat dia masuk rumah sakit, dilakukan pengkajian sistem tubuh setiap pergantian jaga. Informasi yang diperoleh hanya dipergunakan pada klien dengan masalah keperawatan yang kronis

\section{FOCUS (PROCESS ORIENTED SYSTEM)}

Pencatatan model Focus menggambarkan suatu proses pencatatan yang memfokuskan pada keluhan klien, dokumentasi ini digunakan untuk mengorganisir dokumentasi asuhan keperawatan. Jika menuliskan catatan perkembangan, gunakan format DAR (DataActionRespon) dengan 3 kolom.

Ciri dokumentasi asuhan keperawatan yang baik menurut Potter dan Perry (2010) berdasarkan atas: pertama; fakta (faktual basis), kedua; akurat (accuracy) ketiga; lengkap (completeness), 
keempat; ringkas (conciseness), kelima; terorganisir sedangkan keenam dan ketujuh adalah waktu yang tepat (time liness) dan bersifat mudah dibaca (legibility).

Adapun prisip-prinsip dalam melakukan dokumentasi yaitu: a. Dokumen merupakan suatu bagian integral dari pemberian asuhan keperawatan. b. Praktik dokumentasi bersifat konsisten. c. Tersedianya format dalam praktik dokumentasi. d. Dokumentasi hanya dibuat oleh orang yang melakukan tindakan atau mengobservasi langsung klien. e. Dokumentasi harus dibuat sesegera mungkin. f. Catatan harus dibuat secara kronologis. g. Penulisan singkatan harus menggunakan istilah yang sudah berlaku umum dan seragam. h. Tuliskan tanggal, jam, tanda tangan, dan inisial penulis. i. Catatan harus akurat, benar, komplit, jelas, ringkas, dapat dibaca, dan ditulis dengan tinta. j. Dokumentasi adalah rahasia dan harus disimpan dengan benar

Ciri dokumentasi asuhan keperawatan yang baik menurut Potter dan Perry (2010) berdasarkan atas: pertama; fakta (faktual basis), kedua; akurat (accuracy) ketiga; lengkap (completeness), keempat; ringkas (conciseness), kelima; terorganisir sedangkan keenam dan ketujuh adalah waktu yang tepat (time liness) dan bersifat mudah dibaca (legibility).

\section{Penutup}

Salah satu tugas dan tanggungung jawab perawat adalah melakukan pendokumentasian mengenai intervensi yang telah dilakukan. Oleh karena itu perawat perlu menyusun suatu model dokumentasi baru yang lebih efisien dan lebih bermakna dalam pencatatan dan penyimpanan. Pendokumentasian sangat penting bagi perawat karena sebagai dasar hukum tindakan keperawatan yang sudah di lakukan jika suatu saat nanti ada tuntutan dari pasien.

\section{Daftar Pustaka}

Ardenny dan Hirzal. 2016. EFEKTIVITAS FORMAT PENDOKUMENTASIAN KEPERAWATAN MODEL PROBLEM ORIENTED RECORD (POR) TERHADAP KEMUDAHAN PENGGUNAANNYA OLEH PERAWAT DI RAWAT JALAN RSUD PETALA BUMI PEKANBARU. Jurnal Kesehatan. 7 (3), 366-376

Dinarti \& Y . M . 2017. DOKUMENTASI KEPERAWATAN. Jakarta : KEMENTERIAN KESEHATAN REPUBLIK INDONESIA

ERIYANI. 2020. DOKUMENTASI KEPERAWATAN. Medan : Sekolah Tinggi Ilmu Kesehatan BINALITA SUDAMA

FATIMAH. 2017. “ PENERAPAN MODEL PENDOKUMENTASIAN ASUHAN KEPERAWATAN PADA RUANG RINRA SAYANG II DI RSUD HAJI MAKASSAR “. 
Skripsi. FAKULTAS KEDOKTERAN DAN ILMU KESEHATAN . UNIVERSITAS ISLAM NEGERI ALAUDDIN : MAKASSAR .

Lestari, A . W. 2019. Hubungan Motivasi Perawat dengan Pelaksanaan Dokumentasi Keperawatan di Rumah Sakit Islam Sultan Agung Semarang. Prosiding SEMINAR NASIONAL MAHASISWA .

Olfah, Y . 2016. DOKUMENTASI KEPERAWATAN. Jakarta : KEMENTERIAN KESEHATAN

Rosmalia,D dkk. 2014. Analisis Sistim Manajemen Dokumentasi Keperawatan pada Poliklinik Gigi Rumah Sakit di Bukittinggi. Jurnal Kesehatan Andalas. 3(1), 967 972

Salmawati. 2013. “ FAKTOR YANG BERHUBUNGAN DENGAN PELAKSANAAN DOKUMENTASI ASUHAN KEPERAWATAN DI RUANG PERAWATAN RSUD LABUANG BAJI MAKASSAR “. Skripsi. KEPERAWATAN. UNIVERSITAS ISLAM NEGERI ALAUDDIN : MAKASSAR.

Simamora, R. (2009). Dokumentasi Proses Keperawatan.

Simamora, R. H., Purba, J. M., Bukit, E. K., \& Nurbaiti, N. (2019). Penguatan Peran Perawat Dalam Pelaksanaan Asuhan Keperawatan Melalui Pelatihan Layanan Prima. JPPM (Jurnal Pengabdian Dan Pemberdayaan Masyarakat), 3(1), 25-31.

Wirawan dkk. 2013. HUBUNGAN ANTARA SUPERVISI KEPALA RUANG DENGAN PENDOKUMENTASIAN ASUHAN KEPERAWATAN DI RUMAH SAKIT UMUM DAERAH AMBARAWA. Jurnal Managemen Keperawatan . 1 (1), 1 - 6

Yanti, R . I. \& SSSSSSSBambang . 2013 . HUBUNGAN KARAKTERISTIK PERAWAT, MOTIVASI, DAN SUPERVISI DENGAN KUALITAS DOKUMENTASI PROSES ASUHAN KEPERAWATAN. Jurnal Managemen Keperawatan. 1 (2), 107 - 114 